See discussions, stats, and author profiles for this publication at: https://www.researchgate.net/publication/343737671

\title{
The Attitudes of Medical Students for Their Roles and Social Accountability in the COVID-19 Pandemic Era
}

Preprint · August 2020

DOI: $10.31234 /$ off.io/478ef

\section{CITATIONS}

0

10 authors, including:

Aly Suh

Sungshin Women's University

109 PUBLICATIONS 1,227 CITATIONS

SEE PROFILE

(3.) Seockhoon Chung

(Ii)

Asan Medical Center

154 PUBLICATIONS 1,428 CITATIONS

SEE PROFILE

Some of the authors of this publication are also working on these related projects:

Project AMC 7 hours sleep study series View project

Project $\mathrm{AMC}$ Sleep + Kids View project
Jangho Park

Ulsan University Hospital

28 PUBLICATIONS 196 CITATIONS

SEE PROFILE 


\section{The Attitudes of Medical Students for Their Roles and Social Accountability in the COVID-19 Pandemic Era}

Jihoon Hong1, Ikjae Jung¹, Mingeol Park ${ }^{1}$, Kyumin Kim², Sungook Yeo², Joohee Lee², Sooyeon Suh ${ }^{3}$, Youjin Hong ${ }^{4}$, Jangho Park ${ }^{5 *}$, Seockhoon Chung2*

University of Ulsan College of Medicine, Seoul Korea ${ }^{1}$

Department of Psychiatry, Asan Medical Center, University of Ulsan College of Medicine ${ }^{2}$ Department of Psychology, Sungshin Women's University, Seoul, Korea Department of Psychiatry, Gangneung Asan Hospital, University of Ulsan College of Medicine Department of Psychiatry, Ulsan University Hospital, University of Ulsan College of Medicine ${ }^{5}$

12

Correspondence ${ }^{*}$ Two authors equally contributed

Jangho Park, MD, PhD, Department of Psychiatry, Ulsan University Hospital, University of Ulsan College of Medicine, 877 Bangeojinsunhwando-ro, Dong-gu, Ulsan 44033, Republic of Korea, Tel +82-52-2508945,

E-mail: parkjangho@uuh.ulsan.kr

Seockhoon Chung, MD, PhD, Department of Psychiatry, Asan Medical Center, University of Ulsan College of Medicine, 86 Olympic-ro 43-gil, Songpa-gu, Seoul 05505, Korea, Tel +82-2-3010-3411, Fax +82-2-4858381, E-mail schung@amc.seoul.kr 
Abstract

\section{Introduction}

This study aimed to explore the attitude of medical students toward their roles and social accountability in this pandemic era. An online survey asked questions covering the topics of 1 ) the role of medical students in the pandemic era; 2) Medical education in the 'new normal,' and 3) the impact of COVID-19 on medical students.

\section{Methods}

The online survey was distributed to medical students, graduates, and professors in a single South Korean medical school. Anxiety symptom rating scales, including the Stress and Anxiety to Viral Epidemic - 6 (SAVE-6) scale and the Generalized Anxiety Disorder - 7 (GAD-7) scale, were also applied to measure participant anxiety level.

\section{Results}

213 medical students, 180 graduates, and 181 professors participated in this online survey. Medical students indicated their willingness to join the healthcare response to the COVID-19 pandemic if requested; however, graduates and professors recommended that medical students continue their medical school curriculum. In the new normal era, adequate knowledge of COVID-19 infection and spread must be considered for the continuation of clinical clerkships during the pandemic. Overall, medical students who indicated anxiety about treating possible or confirmed cases rated higher on the SAVE-6 scale. Finally, medical students who reported that COVID-19 had an influence on their studies and daily life rated higher on the GAD-7 scale.

\section{Conclusion}


60 Social accountability is an important issue for medical students in the pandemic era. At the same

61 time, cultivating professionalism is also important for the readiness for the future healthcare 62 responses.

64 Key words: COVID-19, pandemic, medical students, education 
Coronavirus disease-19 (COVID-19) is an infectious respiratory disease caused by a novel type of the coronavirus (SARS-CoV-2), which spread throughout China and around the world since the first reported case in Wuhan, Hubei Province, in December 2019 1. In Korea, since the first reported case on January 20, 2020, the COVID-19 crisis level has remained at the 'severe' level. Around the world, 12,322,395 patients have tested positive for COVID-19. Korea has reported

13,440 cases, with 298 deaths due to COVID-19-related causes. COVID-19 remains prevalent in Korea, which had 331 confirmed COVID-19 cases and six deaths during the week of 2020/7/5 to $2020 / 7 / 11^{2}$.

Past studies show that medical student curriculum and daily life undergoes multiple changes during times of pandemic, war, or disaster. Moreover, these studies indicate that their social role changes as well during these difficult times. In a survey of Belgian senior medical students at the time of the H5N1 virus outbreak in Europe, 70\% responded positively to the idea of taking part in primary care. Furthermore, $82.3 \%$ of the medical students stated that they would take care of patients who were positive for an epidemic disease ${ }^{3}$. Also, in some cases, medical students have taken roles as frontline healthcare workers ${ }^{4}$. For example, during the Spanish Flu of 1918 1919, medical and nursing students supplemented under-staffed medical systems 5 . Moreover, during pandemics such as COVID-19, teaching methods must be altered to minimize direct contact between professors and students. For example, during the SARS epidemic, the Singapore Medical School developed a web-based learning method for medical students 6 . Similarly, many medical schools in Korea are conducting online education during the current coronavirus pandemic. However, problems may arise as there may be some unfamiliarity with online teaching methods among students and professors. Additionally, students may feel uneasy with infectious diseases practices due to delays in learning about infectious diseases ${ }^{7}$. Medical 
students can also be vulnerable to the stressors associated with infectious diseases. The dangers associated with exposure to infectious diseases, such as COVID-19, can often lead to stress among medical staff, as they often fear transmission of the virus to their families and friends 8 . This stress can also significantly affect medical students, who are the closest group to a hospital among non-medical personnel. The threats associated with highly infectious diseases are also linked to anxiety symptoms among medical students ${ }^{7}$.

Unlike other disasters, infectious diseases directly affect medical students due to their association with hospitals and medical staff. Currently, the role medical students play during a pandemic varies. This may range from not participating at all to working as frontline health workers. Some medical students have even created Facebook pages to share COVID-19-related information with the public. In this respect, an examination of the societal responsibilities of medical students during a pandemic in this thesis has great significance. It will be also important to assess the stress of medical students and the impact of medical education and COVID-19 on their lives. Also, so far, there has been little research focusing on the stress of a particular group of medical students compared with medical staff and the general public in infectious diseases. In this regards, it will also be important to assess the stress of medical students sharing the personalities of the two groups and the impact of COVID-19 on their lives. In addition, the survey of online medical education in this study will help direct future medical education decision making during pandemics.

In this study, an online survey was conducted with the cooperation of medical students, graduates, and professors at the University of Ulsan College of Medicine to identify the following three objectives: 1) the role of medical students in the pandemic era, 2) Medical education in the 'new normal', and 3) the impact of COVID-19 on medical students. The questionnaire is largely divided into two sections. This study aimed to explore the attitudes and social roles of medical 

students during the COVID-19 pandemic.

122

123 


\section{Study design}

This study was performed using an online survey for medical students during the COVID-19 pandemic. All of the 213 medical students at the University of Ulsan College of Medicine, Seoul, Korea, participated in the online survey. Responders were rewarded with an e-gift coupon of about 3 dollars. Furthermore, University of Ulsan College of Medicine alumni and professors were also requested to respond to the survey as a control group. Written informed consent was waived, and the study was approved by the Institutional Review Board (2020-1067).

\section{Survey questions}

Survey questions were developed by a team consisting of 3 medical students, 3 psychiatric residents, and 3 psychiatric professors. We reviewed the previous literature ${ }^{4,9,10}$, and developed questions to explore the attitudes of medical students about their role during the current pandemic and medical education in the 'new normal'. The online survey was designed for evaluating how medical students think about 1) the roles of medical students in the pandemic era, 2) medical education in the 'new normal', and 3) the impact of COVID-19 on medical students.

\section{1) The role of medical students in the pandemic era}

This part of the survey was aimed at exploring the attitudes medical students have toward their societal duties during the pandemic. The following questions were asked: 
A1. How interested are you in COVID-19? A2. How important is social responsibility to medical students? A3. In some countries, medical students work as frontline healthcare workers. Are you positive about this? A4. Do you think students are ready to be in the medical field in a pandemic situation? A5. If you are requested by a hospital or university to help during the COVID-19 pandemic, are you willing to participate in patient care or assistance? A6. Do you agree with having early graduation or being awarded a temporary license in the event a new infectious disease situation occurs in the future and students are required to enter the medical field quickly? A7. Do you think you can practice medicine even though you are a trainee?

\section{2) Medical education in the 'new normal'}

In a pandemic situation, online education often replaces person-to-person education in medical schools. However, since clinical experience in the hospital is also an important part of the medical school curriculum, the change to online education may influence the clinical ability of medical students. Therefore, we asked the following questions:

B1. Do you think that medical school education is working properly during the COVID-19 pandemic? B2. Do you think you should graduate on schedule and practice medicine, even if your medical school training is not complete due to the ongoing pandemic situation? B3. To what extent do you feel medical school education must change to fit into the new normal era? B4. How should hands-on clinical practice education be reduced or replaced during the pandemic? B5. During COVID-19, how do you think patients will accept students who are trainees?

\footnotetext{
3) The impact of COVID-19 on medical students
} 
This part was just for medical students and included questions regarding the influence of COVID-19 on medical student education and daily lives. Therefore, we asked the following questions:

C1. How has your amount of study time changed compared to before the COVID-19 situation?

C2. How has your level of academic-related stress changed compared to before the COVID-19 situation? C3. How much has the current COVID-19 situation affected your studies? C4. Are you afraid of interacting with a typical patient (during clinical practice) as a medical student? C5. Are you afraid of interacting with a suspected coronavirus patient as a medical student

\section{Rating scales}

To measure anxiety symptoms of subjects, we asked the following two questions: 1.) Do you currently think you are depressed or anxious or do you need help with your mental health? 2.) Did you experience being quarantined due to COVID-19 infection?

\section{1) Stress and Anxiety to Viral Epidemic - 6 (SAVE-6) scale}

The SAVE-6 scale is the anxiety response to a viral epidemic, and a subcategory of the SAVE-9 scale ${ }^{11}$, that was initially developed for assessing work-related stress and anxiety responses of healthcare workers to viral epidemics in COVID-19 ${ }^{12}$. The SAVE-9 was clustered into the 
following two factors: 1) anxiety response to viral epidemics and 2) work-related stress. Each item can be rated on a 5-point scale ranging from 0 (never), 1 (rarely), 2 (sometimes), 3 (often), and 4 (always). The cut-off of the total SAVE-9 scale score and anxiety subscale score for higher anxiety levels were found to be 22 and 15, respectively. In this study, only the anxiety response to viral epidemics subcategory (SAVE-6) was applied to all subjects, since it was not appropriate to apply the work-related stress subcategory medical students who are not currently working in the hospital.

\section{2) General Anxiety Disorder - 7 (GAD-7) scale}

GAD-7 is a seven-item rating scale for assessing general anxiety. Each item can be scored on a three-point Likert scale $(0=$ not at all to $3=$ nearly every day $)$, and the total score of GAD-7 can range from 0 to 21. Cut-off scores for anxiety include 0-4 (minimal), 5-9 (mild anxiety), 10-14 (moderate), and 15-21 (severe) ${ }^{13}$.

\section{Statistical analysis}

The statistical analyses were done using the SPSS program (Version 21.0 for Windows, IBM Corp., Armonk, NY). The clinical characteristics were presented as mean \pm standard deviation. The significance level for all analyses was defined as two-tailed $p<0.01$. An ANOVA test with a Scheffe post-hoc analysis for continuous variables or a Chi-square test for categorical variables was used for between-group analyses. Spearman correlation was done to explore the relationship between symptom rating scores and the question responses. 
218 A total of 213 medical students, 180 graduates, and 181 professors at the University of Ulsan

219 College of Medicine participated in this online survey. About $77 \%(\mathrm{~N}=445)$ were male, and $7 \%$

$220(\mathrm{~N}=41)$ were now seeking help for depression and/or anxiety. Moreover, about $3 \%(\mathrm{~N}=15)$ were quarantined due to COVID-19 infection. There was no significant difference in general anxiety, as measured by GAD-7, among the three groups. However, a slightly lower level of anxiety was observed in the graduate group regarding viral epidemics, as measured by SAVE-6 (Table 1).

224

Table 1. Demographic characteristics of subjects $(\mathrm{N}=574)$

\begin{tabular}{|l|c|c|c|c|}
\hline Variables & $\begin{array}{c}\text { Medical } \\
\text { students } \\
(\mathrm{N}=213)\end{array}$ & $\begin{array}{c}\text { Graduates } \\
(\mathrm{N}=180)\end{array}$ & $\begin{array}{c}\text { Professors } \\
(\mathrm{N}=181)\end{array}$ & $\mathrm{p}$-value \\
\hline Sex (male) & $150(70.8 \%)$ & $155(86.1 \%)$ & $140(77.3 \%)$ & 0.08 \\
\hline Career year from admission to medical school & $3.0 \pm 1.7$ & $17.6 \pm 8.2$ & $27.9 \pm 7.8$ & $<0.01$ \\
\hline $\begin{array}{l}\text { Now, do you think you are depressed or anxious, } \\
\text { or do you need help for your mood state? (Yes) N } \\
\text { (\%) }\end{array}$ & $15(7.1 \%)$ & $11(6.1 \%)$ & $15(8.3 \%)$ & 0.68 \\
\hline $\begin{array}{l}\text { Did you experience being quarantined due to } \\
\text { infection with COVID-19? (Yes) N (\%) }\end{array}$ & $2(0.9 \%)$ & $8(4.5 \%)$ & $5(2.8 \%)$ & 0.21 \\
\hline Symptoms assessments & & & & \\
\hline Generalized Anxiety Disorder-7 (GAD-7) & $1.9 \pm 3.0$ & $1.6 \pm 2.8$ & $1.5 \pm 2.7$ & 0.39 \\
\hline $\begin{array}{l}\text { Stress and Anxiety to Viral Epidemic-6 (SAVE- } \\
6)\end{array}$ & $11.0 \pm 4.6$ & $10.7 \pm 4.3$ & $11.9 \pm 4.4$ & 0.02 \\
\hline
\end{tabular}


Table 2. Responses of medical students, graduates, and professors to survey questionnaires

\begin{tabular}{|c|c|c|c|c|}
\hline Survey & $\begin{array}{l}\text { A. Students } \\
(\mathrm{N}=\mathbf{2 1 3})\end{array}$ & $\begin{array}{l}\text { B. Graduates } \\
(\mathrm{N}=\mathbf{1 8 0})\end{array}$ & $\begin{array}{c}\text { C. } \\
\text { Professors } \\
(\mathrm{N}=181)\end{array}$ & p value \\
\hline \multicolumn{5}{|l|}{ A. The role of medical students in the pandemic era } \\
\hline $\begin{array}{l}\text { A1. How interested are you in COVID-19? } \\
\text { (0: never } \sim 10 \text { : very interested })\end{array}$ & $7.06 \pm 1.72$ & $7.63 \pm 1.88$ & $8.28 \pm 1.69$ & $\mathrm{~A}<\mathrm{B}<\mathrm{C}$ \\
\hline $\begin{array}{l}\text { A2. How important is social responsibility to medical students? } \\
\text { (0: not important } \sim 10 \text { : very important })\end{array}$ & $7.07 \pm 1.81$ & $5.88 \pm 2.10$ & $6.95 \pm 2.07$ & $\mathrm{~A}=\mathrm{C}>\mathrm{B}$ \\
\hline $\begin{array}{l}\text { A3. In some countries, medical students work as frontline } \\
\text { healthcare workers. Are you positive about this? } \\
\quad \text { ( } 0 \text { : very negative } \sim 10 \text { : very positive) }\end{array}$ & $6.19 \pm 2.21$ & $4.99 \pm 2.66$ & $5.65 \pm 2.57$ & $\mathrm{~A}>\mathrm{B}=\mathrm{C}$ \\
\hline $\begin{array}{l}\text { A4. Do you think students are ready to be in the medical field in } \\
\text { a pandemic situation? } \\
\text { (0: never } \sim 10 \text { : definitely })\end{array}$ & $3.27 \pm 2.22$ & $4.17 \pm 2.64$ & $4.64 \pm 2.22$ & $\mathrm{~A}<\mathrm{B}=\mathrm{C}$ \\
\hline $\begin{array}{l}\text { A5. If you are requested by a hospital or university to help } \\
\text { during the COVID-19 pandemic, are you willing to participate in } \\
\text { patient care or assistance? } \\
\text { (0: never } \sim 10 \text { : definitely) }\end{array}$ & $7.16 \pm 2.04$ & $4.48 \pm 3.31$ & $5.80 \pm 2.73$ & $\mathrm{~A}>\mathrm{C}>\mathrm{B}$ \\
\hline $\begin{array}{l}\text { A6. Do you agree with having an early graduation or being } \\
\text { awarded a temporary license in the event a new infectious disease } \\
\text { situation occurs in the future and students are required to enter } \\
\text { the medical field quickly? } \\
\quad \text { (0: disagree } \sim 10 \text { : agree) }\end{array}$ & $5.32 \pm 2.72$ & $3.31 \pm 2.89$ & $3.30 \pm 3.07$ & $\mathrm{~A}>\mathrm{B}=\mathrm{C}$ \\
\hline $\begin{array}{l}\text { A7. Do you think you can practice medicine even though you are } \\
\text { a trainee? (Yes) }\end{array}$ & $65.2 \%$ & $48.3 \%$ & $58.6 \%$ & $\mathrm{~A}>\mathrm{C}>\mathrm{B}$ \\
\hline \multicolumn{5}{|l|}{ B. Medical education in the 'new normal' } \\
\hline $\begin{array}{l}\text { B1. Do you think that medical school education is working } \\
\text { properly during the COVID-19 pandemic? } \\
\text { (0: disagree } \sim 10 \text { : agree) }\end{array}$ & $5.82 \pm 2.02$ & $4.81 \pm 1.70$ & $4.69 \pm 2.03$ & $\mathrm{~A}>\mathrm{B}=\mathrm{C}$ \\
\hline $\begin{array}{l}\text { B2. Do you think you should graduate on schedule and practice } \\
\text { medicine, even if your medical school training is not complete due } \\
\text { to the ongoing pandemic situation? } \\
\text { (0: never } \sim 10 \text { : definitely) }\end{array}$ & $6.99 \pm 1.93$ & $6.96 \pm 1.92$ & $6.97 \pm 2.08$ & $A=B=C$ \\
\hline $\begin{array}{l}\text { B3. To what extent do you feel medical school education must } \\
\text { change to fit into the 'new normal' era? } \\
\quad(0 \text { : not needed to be changed } \sim 10 \text { : definitely to be } \\
\text { changed) }\end{array}$ & $6.76 \pm 1.84$ & $7.02 \pm 1.96$ & $7.80 \pm 1.49$ & $\mathrm{C}>\mathrm{A}=\mathrm{B}$ \\
\hline $\begin{array}{l}\text { B4. How should hands-on clinical practice education be reduced } \\
\text { or replaced during the pandemic? (Needs to be reduced vs. } \\
\text { maintained) }\end{array}$ & $\begin{array}{l}51.9 \% \text { vs. } \\
48.1 \%\end{array}$ & $\begin{array}{l}46.6 \% / \\
53.4 \%\end{array}$ & $\begin{array}{l}52.5 \% / \\
47.5 \%\end{array}$ & 0.47 \\
\hline $\begin{array}{l}\text { B5. During COVID-19, how do you think patients will accept } \\
\text { students who are trainees? (same as usual / positively / } \\
\text { negatively) }\end{array}$ & $\begin{array}{l}52.8 \% / 4.7 \% \\
\quad / 42 \%\end{array}$ & $\begin{array}{c}50.6 \% / 6.7 \% \\
/ 42.8 \%\end{array} \mid$ & $\begin{array}{c}50.0 \% / 7.2 \% \\
/ 41.6 \%\end{array}$ & 0.27 \\
\hline
\end{tabular}




\section{The role of medical students in the pandemic era}

Survey questions are shown in Table 2. The level of interest in the COVID-19 pandemic was

To the question of "Do you think you can practice medicine even though you are a trainee? (A7)," $65.2 \%(\mathrm{~N}=139)$ of students and $54.6 \%(\mathrm{~N}=197)$ of graduates and professors answered "yes" 
$(\mathrm{P}<0.01)$. The work being performed by medical students can be observation, history taking, patient education, telephone consultation, transfer of test results to patients, case management for discharged patients, and assistance for various procedures.

For those who answered that students should "never be involved in clinical practice," 79.5\% $(\mathrm{N}=66 / 83)$ of medical students explained that the reason they answered that way was due to "lack of ability for clinical practice," followed by "medical license issue (N=9/83, 10.8\%)," and finally "students can be carriers of the virus $(\mathrm{N}=7 / 83)$." To explain their reasoning why they believe medical students "should never be involved in clinical practice," graduates and professors answered that it was due to "lack of ability for clinical practice $(36.4 \%, \mathrm{~N}=64 / 176)$," "medical license issue $(\mathrm{N}=48 / 176,27.3 \%), "$ "students can be a carrier for the virus $(\mathrm{N}=17 / 176$, 9.7\%)," and "relevant and appropriate reward for students ( $\mathrm{N}=12 / 176,6.8 \%) . "$

For the rewards to the medical students for their work, 65.7\% $(\mathrm{N}=377 / 574)$ of all subjects answered "grading or credit for volunteering activity" or "monetary compensation $(22.1 \%$, $\mathrm{N}=127 / 574$ ). Just $9 \%$ of medical students and $8.9 \%$ of graduates and professors answered "volunteer".

\section{Medical education in the 'new normal'}

For the question of "Do you think that medical school education is working properly during the COVID-19 pandemic? (B1)," the level of agreement among graduates and professors was lower than medical students. For the question of "To what extent do you feel medical school education must change to fit into the 'new normal' era? (B3)," the level of agreement of graduates was higher than medical students or professors. To a question of "Do you think you should graduate 
on schedule and practice medicine, even if your medical school training is not complete due to the ongoing pandemic situation? (B2)," there was no significant difference among the three groups.

To the question of "How should hands-on clinical practice education be reduced or replaced during the pandemic? (B4)," $51.9 \%$ of medical students, $46.6 \%$ of graduates, and $52.5 \%$ of professors answered that clinical clerkships should be reduced. As to the reasons for this reduction, 47.4\% ( $\mathrm{N}=64 / 135)$ of students answered that they "worry that students will spread the virus" and that it is "not possible for a regular clinical clerkship (24.4\%)." However, graduates and professors reasoned that they "worry that students can be infected $(38.2 \%$, $\mathrm{N}=76 / 199)$ )" and that it is "not possible for a regular clinical clerkship (33.7\%)". Additionally, to the question of "How do medical students gain clinical experience in the pandemic era?" $54.9 \%$ $(\mathrm{N}=315)$ of all respondents answered "via meeting the patients," followed by "via meeting standardized patients or medical models $(26.3 \%, \mathrm{~N}=145), "$ "online education $(12.8 \%, \mathrm{~N}=73)$," and "virtual reality $(4.3 \%, \mathrm{~N}=25)$.

To the question of "During COVID-19, how do you think patients will accept students who are trainees? (B5)," $52 \%$ of students and $49.9 \%$ of graduates and professors answered, "same as usual," but $42 \%(\mathrm{~N}=89)$ of students and $41 \%(\mathrm{~N}=148)$ of graduates and professors answered "negatively."

Fig 1. The phase outcome, which is the most important in the pandemic era

The phase outcomes of this medical school are 1) professionalism, 2) education \& research, 3) communication \& collaboration, 4) social accountability, 5) self-development, and 6) patient 
care. Students responded that 'social accountability (40\%)' is the most important phase outcome, followed by 'professionalism (30\%),' during the pandemic. However, graduates and professors responded that 'professionalism (44\%)' is the most important phase outcome, followed by 'social accountability (19\%),' in the pandemic era (Fig 1).

\section{Impact of COVID-19 on medical students}

When we consider the 5-point of each question was neutral, students responded as "no change from previous to after the COVID-19" in the amount of study (C1), academic stress (C2). When asked about anxiety-related to interacting with patients during clinical practice, students responded that they were "afraid" to meet possible (C4. 5.11 \pm 2.60$)$ and confirmed (C5, $5.89 \pm$ 2.81) COVID-19 cases. These answers were significantly correlated with the viral epidemicspecific anxiety scale (SAVE-6) score. The impacts of COVID-19 on studying (C6), daily life (C7), and social role (C8) of medical students were rated as higher than neutral, and these responses were more significantly correlated with the GAD-7 scores than the SAVE-6 scores.

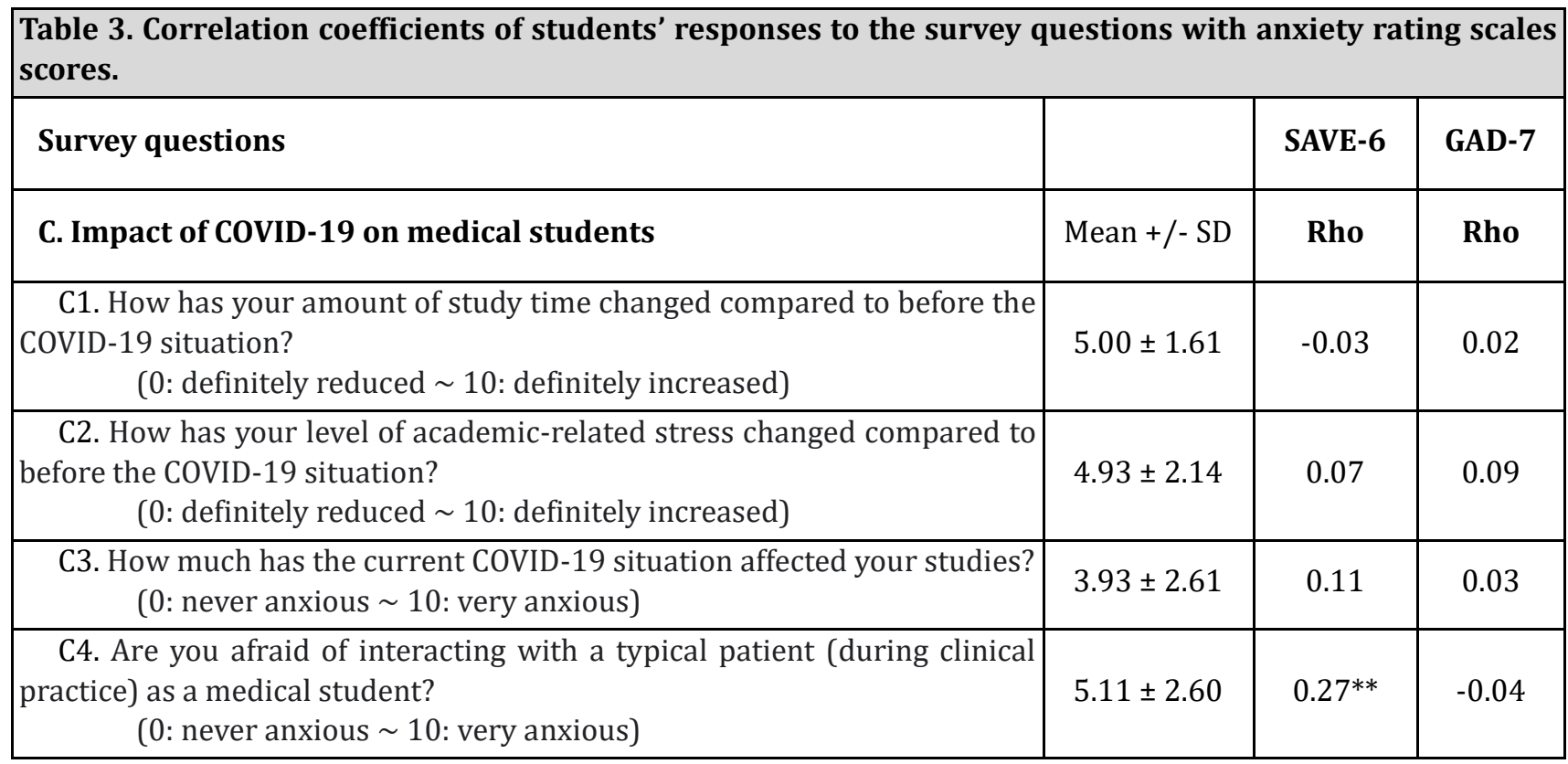




\begin{tabular}{|c|c|c|c|}
\hline $\begin{array}{l}\text { C5. Are you afraid of interacting with a suspected coronavirus patient as } \\
\text { a medical student (during clinical practice)? } \\
(0 \text { : never anxious } \sim 10 \text { : very anxious })\end{array}$ & $5.89 \pm 2.81$ & $0.22^{* *}$ & -0.03 \\
\hline $\begin{array}{l}\text { C6. Are you afraid of interacting with a confirmed coronavirus patient as } \\
\text { a medical student (during clinical practice)? } \\
\text { (0: never affected } \sim 10 \text { : definitely affected) }\end{array}$ & $6.30 \pm 2.47$ & 0.03 & $0.16^{*}$ \\
\hline $\begin{array}{l}\text { C7. How much do you think the current COVID-19 pandemic affects your } \\
\text { life and behavior? } \\
\quad \text { (0: never affected } \sim 10 \text { : definitely affected) }\end{array}$ & $8.26 \pm 1.57$ & 0.03 & $0.21^{*}$ \\
\hline $\begin{array}{l}\text { C8. How much do you think the current COVID-19 pandemic affects your } \\
\text { role as a medical student? } \\
\quad \text { (0: never affected } \sim 10 \text { : definitely affected) }\end{array}$ & $6.24 \pm 2.21$ & 0.07 & $0.21 *$ \\
\hline
\end{tabular}

$321 * \mathrm{p}<0.05{ }^{* *} \mathrm{p}<0.01$

Discussion

In this study, we observed differences in how medical students and graduates or professors view

the role of medical students during the current pandemic. First, the level of interest in COVID-19

was relatively lower in the medical student group compared to the graduate or professor group.

Moreover, medical students indicated that they do not feel fully qualified to work in a clinical

environment during the pandemic. However, they did respond that they would voluntarily aid in

healthcare environments upon request. In contrast, graduates and professors believe that

medical students are ready to join the frontline of healthcare services, but they still value more education for medical students. Second, in the new normal era, medical students expressed their approval of changes in the medical education system during COVID-19. Specifically, medical students were in favor of a reduction in clinical clerkships during the current pandemic, which was stated to be because of fears associated with transmitting infections to patients. However, while graduates and professors also were in favor of reduced clinical clerkships, they reasoned that the risk of a patient to student transmission was too great. Third, medical students who reported being afraid of interacting with possible or confirmed COVID-19 cases also rated as 
that COVID-19-related anxiety influenced their study habits and daily life were found to have higher general anxiety (GAD-7).

\section{The role of medical students in the pandemic era}

Looking at the differences in attitudes toward societal responsibilities between medical students and graduates, we found that, in general, medical students wanted to actively participate in helping society through a medical environment. In contrast, graduates argued that education and professionalism should be fostered rather than social participation. Although, as stated above, medical students showed a lower interest in the coronavirus, they are willing to actively participate in society for three reasons. First, the current medical school curriculum strongly emphasizes learning about societal responsibilities, such as humanities, social sciences, and medical ethics ${ }^{14}$. Classical medical education had focused more on medicine itself, while medical education in modern society puts a greater emphasis on not only medicine, but also on morality, humanity skills, and social responsibilities. Second, graduates and faculty members tend to worry about their students' participation in the medical field due to their own experiences. There is also a possibility that students might have expressed their opinions rather easily because they have not yet had direct participation in the medical field. Graduates and professors, who can encourage student growth into independent medical personnel, may have expressed opposition to exposing students to dangerous situations while they are not prepared to engage in activities that take into account students' protection and educational aspects at the medical site. Third, unlike graduates, professors can take a more active stance on promoting student societal participation, which may underlie the more positive responses of professors regarding the societal participation of medical students (A2, A5, and A7) compared to graduates. This is likely because, unlike graduates group, professors not only play the role of health care professionals while treating patients during pandemics, but they also educate and train medical 
students. As such, the pandemic situation can be an educational opportunity to develop competent and warm-hearted doctors ${ }^{15}$.

Social factors that may affect these outcomes should also be considered. It should be considered that opinions may vary depending on how sufficient the workforce, medical resources, medical supplies, etc. of the country's medical personnel are. During COVID-19, Korea has accomplished a relatively successful quarantine due to the extensive medical expertise, powerful workforce, and a sufficient amount of medical supplies. Moreover, while medical school graduates who are actually actively treating patients may support the idea of medical students participating in the current pandemic response, it may be more effective long term for students to focus more on their current studies. This long-term foresight can help Korea be more prepared for future pandemic situations, rather than exposing students to the current dangers. Due to the COVID-19 pandemic, countries that lack sufficient medical staff (the U.S., South Africa, Brazil) are seeking alternatives, such as early graduation of medical students, use of retired doctors, and permission of state-by-state medical licenses 16,17 . Additionally, easing regulations for medical licenses is also being suggested by medical professionals in those countries ${ }^{18}$.

\section{Medical education in 'new normal'}

Taking into account how various countries have altered their medical school systems in the 'new normal' era, graduates in this study indicated more progressively than medical students or professors the need for change in medical education. Globally, education is rapidly changing in the wake of the coronavirus crisis, with an increasing need to take into account the various interests and requirements of students. In fact, various educational platforms are being used to combat the loss of access to physical schools during the pandemic. Examples include the 
Coursera, which is led by Stanford ${ }^{19}$, and K-MOOC, which is underway in Korea ${ }^{20}$. These same platforms may be useful for medical school education.

In this study, in regard to a question about the effectiveness of medical education during the COVID-19 pandemic (B1), students more favorably viewed the current medical education system than professors and medical school graduates. Currently, most medical schools in Korea are offering online lectures for untact lectures. In this regard, students who often use online platform-style lectures, dating back to high school, indicate that using online media does not hinder education; however, graduates and professors, who value clinical practice, have expressed doubts about the effectiveness of online lectures.

In the case of clinical practice, $54.9 \%(\mathrm{~N}=315)$ of all responses answered: "via meeting the patients." Students, professors, and graduates all agree that it is critically important for students to interact directly with patients to gain important clinical experience. However, students worried that they would be perceived as transmitters of COVID-19 and, thus, patients would look at them negatively. Consequently, many students responded that clinical practice should be reduced or replaced (51.4\%, $\mathrm{N}=109 / 211)$. Students preferred changes in simulated patients and models $(24.2 \%, \mathrm{~N}=51 / 211)$, online learning $(11.4 \%, \mathrm{~N}=24 / 211)$, and virtual reality $(4.7 \%$, $\mathrm{N}=10 / 211$ ) in future medical practices. Currently, clinical practice during pandemics has checked the results of students' COVID-19 infection tests and has shown passive responses to ensure safety from infectious diseases by himself and the hospital. If COVID-19 is prolonged, or a new global epidemic occurs, medical treatment will need to try various alternatives to physical meetings with patients. Some departments at the Asan Medical Center in Seoul, one of the educational hospitals of the University of Ulsan College of Medicine, introduced online learning in some curricula during student clinical practice. For example, a conference on internal medicine cases for Policlinic trainees at Asan Medical Center was conducted via online lectures. Also, during a pediatrician practical course, students attended the course through Skype. 
Another important issue is how to best utilize face-to-face meetings with patients in a safe environment amid such changes in clinical practice. Finally, an evaluation of medical education according to the changing environment must also be carried out, so that medical students can be educated in a safe environment without degrading the quality of education. It not only seeks a variety of changes to ensure that there is no degradation in quality but also helps to ensure student safety is taken into account.

Medical students expressed greater apprehension of directly interacting with COVID-19 suspected patients and COVID-19 confirmed patients relative to the general patient population. Since the spread of infectious diseases is regulated by contact, nasal mucus, and airborne transmission, equipment for safe clinical practice must be provided, and clerkship| should be conducted. In addition, evaluation and treatment of anxiety and psychological difficulties in the medical student population is critically important during the COVID-19 pandemic. To combat these mental health issues, students should be assigned a counseling office, a professor dedicated to helping with student life, and a homeroom professor.

\section{Impact of COVID-19 on medical students}

First of all, our survey indicated that COVID-19 did not have a significant impact on student academic performance or stress levels (C1, C2). However, COVID-19 did appear to significantly affect academic situations (C6). Specifically, while the method of teaching during the pandemic has changed, the academic burden felt by the medical students was largely unaffected. In this study, the SAVE-6 survey was more correlated with COVID-19-related impacts on clinical practices. Conversely, the GAD-7 survey appeared to represent the impact of COVID-19 on daily life and behavior, as well as academic and social activities. Specifically, the fear of interacting with coronavirus patients during clinical practice, which is generally close to medical practice, 
was better represented in SAVE-6, a subcategory of SAVE-9 first created for medical staff, than GAD-7. Conversely, GAD-7 better revealed the general lives of students. Through GAD-7, it was revealed that medical students belonged to both the medical staff and the public category for COVID-19. Importantly, this paper used a survey to describe the characteristics of actual medical students and, furthermore, confirmed that COVID-19-related stress has many complex aspects, without a single indicator.

The first limitation of this study was that the survey was developed and distributed to members of a single medical school. We think results may vary depending on a school's academic trends and availability of humanities and social education for medical students. Second, it should be taken into account that the survey focused on medical students in Korean, wherein there were sufficient medical resources and medical supplies during the COVID-19 pandemic. However, in countries with medical staff shortages, the need for the help of medical students may lead to different results. In addition, it is possible that the Eastern way of thinking, which places a higher value on the protection of students ${ }^{21}$ than the Western way of thinking ${ }^{22}$, led to graduates and professors expressing their opinions from a more protective perspective.

A third limitation of this study is that the coronavirus-induced anxiety (especially from a living perspective) may have actually been underreported because the survey was conducted after the social system stabilized to a certain extent, as opposed to shortly after the coronavirus outbreak. 
This study attempted to develop a social consensus on the extent to which medical students should play a role within the medical system. This included understanding the role of medical students during new infectious disease outbreaks, which may aid in handling pandemics in the future. Moreover, medical school education must be available on new platforms, while the contents of education should also be carried out to recognize public health care, health care, and medical care as a part of society, and to cultivate the ability to be seen in a big picture. In assessing the effects of COVID-19, anxiety about the infection itself and the social, academic, and daily living effects should be assessed on different scales. We believe this paper can be a starting point for a discussion on the participation of medical students in society by surveying the perception of actual medical students.

\section{Abbreviations}

COVID-19: Coronavirus Disease - 2019

SAVE-6: Stress and Anxiety to Viral Epidemics - 6 items

GAD-7: Generalized Anxiety Disorder - 7 items 


\section{Ethics approval and consent to participate}

486

487

488

489

490

491

492

493

494

495

496

497

498

499

500

\section{Consent for publication}

Not applicable

\section{Availability of data and material}

The datasets generated and/or analysed during the current study are not publicly available due just from an online survey but are available from the corresponding author on reasonable request.

\section{Competing interests}

We have no conflict of interests.

\section{Funding}

This work was supported under the framework of international cooperation program managed by the National Research Foundation of Korea [FY2020K2A9A1A01094956]. The funding was raised for the research against the Coronavirus (COVID-19) pandemic. 
Authors' contributions

508

509

Conceptualization, Methodology; YH, JP, SC

510

511

Data curation, Formal analysis; JH, IJ, MP, KK, SY, JL

512

Software; SC

513

Writing - original draft preparation; JH, IJ, MP,

514

Writing - review \& editing; YH, JP, SC

515

AND all authors have approved the submitted version (and any substantially modified version that involves the author's contribution to the study)

517

518

AND all authors have agreed both to be personally accountable for the author's own contributions and to ensure that questions related to the accuracy or integrity of any part of the work, even ones in which the author was not personally involved, are appropriately investigated, resolved, and the resolution documented in the literature.

\section{Acknowledgement}

We would like to thank all the medical students, graduates, and professors who voluntarily participated in this study. 
1. Chan JF, Yuan S, Kok KH, To KK, Chu H, Yang J, et al. A familial cluster of pneu monia associated with the 2019 novel coronavirus indicating person-to-person tra nsmission: a study of a family cluster. Lancet 2020; 395: 514-523.

2. Weekly report on the COVID-19 situation in the Republic of Korea (As of July 11 , 2020] [https://www.cdc.go.kr/board/board.es?mid=a30501000000\&bid=0031\&list_ no $=367819 \&$ act $=$ view].

3. Mortelmans LJ, De Cauwer HG, Van Dyck E, Monballyu P, Van Giel R Van Turnho ut E. Are Belgian senior medical students ready to deliver basic medical care in case of a H5N1 pandemic? Prehosp Disaster Med 2009; 24: 438-442.

4. Miller DG, Pierson L Doernberg S. The Role of Medical Students During the COVI D-19 Pandemic. Ann Intern Med 2020; 173: 145-146.

5. Calm, Cool, Courageous: Nursing and the 1918 Influenza Pandemic [https://www. nursing.upenn.edu/history/publications/calm-cool-courageous/].

6. Lim EC, Oh VM, Koh DR Seet RC. The challenges of "continuing medical educatio n" in a pandemic era. Ann Acad Med Singap 2009; 38: 724-726.

7. Cao W, Fang Z, Hou G, Han M, Xu X, Dong J, et al. The psychological impact of $t$ he COVID-19 epidemic on college students in China. Psychiatry Res 2020; 287: 1 12934.

8. Maunder R, Hunter J, Vincent L, Bennett J, Peladeau N, Leszcz M, et al. The imm ediate psychological and occupational impact of the 2003 SARS outbreak in a tea ching hospital. CMAJ 2003; 168: 1245-1251.

9. Brisolara KF Smith DG. Preparing Students for a More Public Health-Aware Marke t in Response to COVID-19. Prev Chronic Dis 2020; 17: E56.

10. Valdez-Garcia JE, Erana-Rojas IE, Diaz Elizondo JA, Cordero-Diaz MA, Torres-Quinta nilla A, Esperon-Hernandez RI, et al. The role of the medicine student in COVID19 pandemic. A shared responsibility. Cir Cir 2020; 88: 399-401.

11. Stress and Anxiety to Viral Epidemics - 6 items (SAVE-6) for General Population [www.save-viralepidemic.net].

12. Chung S, Kim H, Ahn M, Yeo S, Kim K, Kang S, et al. Development of the Stress and Anxiety to Viral Epidemics - 9 (SAVE-9) scale for assessing work-related stre ss and anxiety in healthcare workers in response to COVID-19

13. Spitzer RL, Kroenke K, Williams JB Lowe B. A brief measure for assessing genera lized anxiety disorder: the GAD-7. Arch Intern Med 2006; 166: 1092-1097. 
14. Faulkner LR McCurdy RL. Teaching medical students social responsibility: the righ t thing to do. Acad Med 2000; 75: 346-350.

15. Kalet AL, Jotterand F, Muntz M, Thapa B Campbell B. Hearing the Call of Duty: What We Must Do to Allow Medical Students to Respond to the COVID-19 Pande mic. WMJ 2020; 119: 6-7.

16. Meet the Medical Students Becoming Doctors in the Middle of a Pandemic [https: //time.com/5820046/medical-students-covid-19/].

17. Students play an integral role in healthcare delivery: findings from South Africa [ https://www.bizcommunity.com/Article/196/858/206054.html].

18. Immigrant Doctors Fight To Contribute To US COVID-19 Response [https://www.w pr.org/immigrant-doctors-fight-contribute-us-covid-19-response].

19. Coursera [https://www.coursera.org/].

20. K-MOOC [http://www.kmooc.kr/].

21. Chao R Tseng V. Handbook of parenting: Social conditions and applied parenting . Lawrence Erlbaum Associates Publishers, Mahwah, NJ, US, 2002; 59-93.

22. Stewart S MH B. A critical look at parenting research from the mainstream: Prob lems uncovered while adapting Western research to non-Western cultures. Br J D evelopment Psychol 2010; 20: 379-392. 

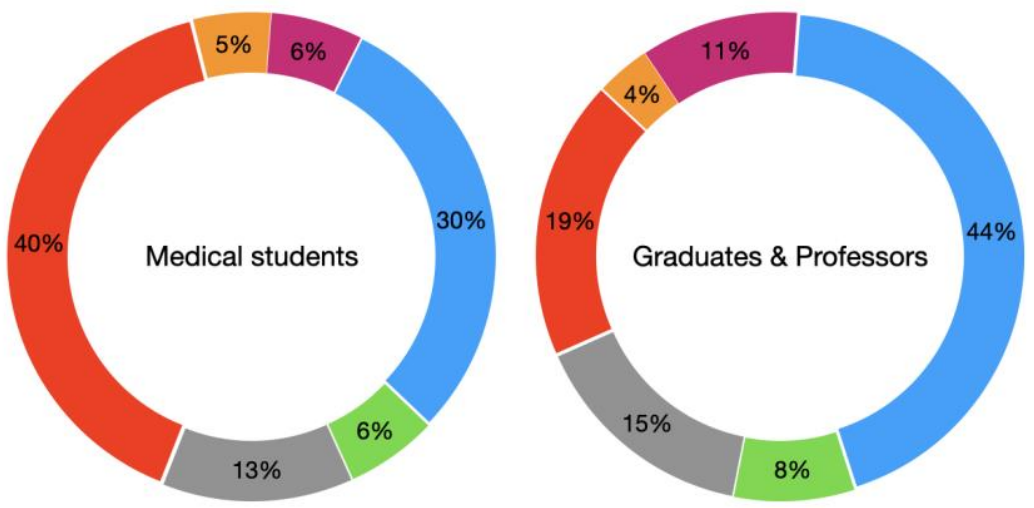

Professionalism

Education \& Research

Communication \& Collaboration

Social accountability

Self-development

Patient care 